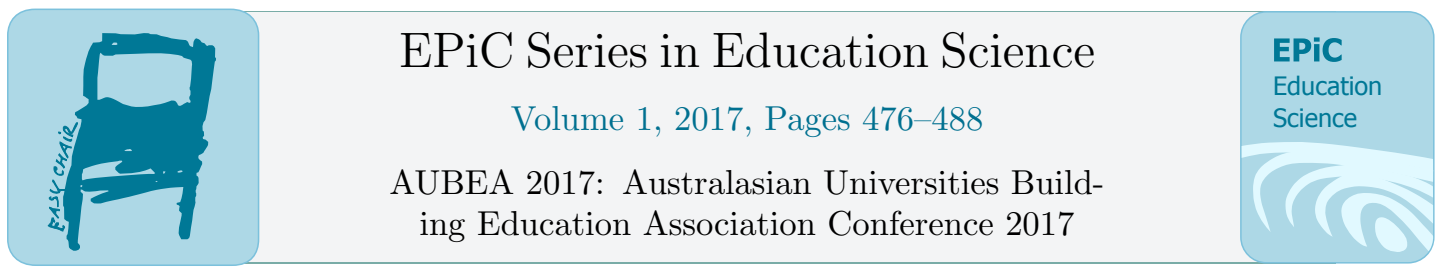

\title{
TRAINING TRANSFER AS THE RESULT OF RATIONAL DECISION-MAKING PROCESS
}

T. Pham, H. Lingard, R. Wakefield, R. Zhang

School of Property, Construction and Project Management, RMIT University, Melbourne, 3001 Australia

tungthanh.pham@rmit.edu.au

\section{ABSTRACT}

Employee training is delivered as a part of most human resource development programs because organizations expect training courses will enhance their employees' performance. However, training may not lead to improved work performance if training transfer does not occur. The lack of training transfer in practice has long been considered as a critical problem. Also, previous theoretical models of training transfer cannot fully explain this phenomenon. As an attempt to solve the training transfer problem, this paper provides a literature review on training transfer and proposes a conceptual model grounded on the Theory of Planned Behaviour.

Keywords: training transfer, models of training transfer, the Theory of Planned Behaviour, literature review

\section{INTRODUCTION}

Human capital plays an important role in organizational success so developing adequate human resource development (HRD) programs is an essential strategy for construction companies (Egbu, 2004). Employee training is delivered as a part of most HRD programs since 
training courses are designed to provide individuals with skills and knowledge that they may use at work (Blundell et al., 1999). Construction firms expect that the acquisition of necessary skills and knowledge will improve their employees' performance, which in turn contributes to organizational success. However, there has been a concern about the effectiveness of training in construction (Gann and Senker, 1998; Wilkins, 2011). Also, even with effective training, which means employees successfully learn and retain the training content, improved work performance cannot be achieved if they do not use their learned skills and knowledge at work. The extent to which trainees apply their acquired skills and knowledge in practice is known as training transfer (Baldwin and Ford, 1988).

Unfortunately, the lack of training transfer is a common problem in various industries (Blume et al., 2010), including the construction industry (Choudhry and Fang, 2008). Because organizations spend billions of dollars annually on employee training (Grossman and Salas, 2011), it can be considered as wasteful if the return of training investment is not fully realized. Despite the importance of training transfer, little research has been conducted to investigate this phenomenon in the construction context (Namian et al., 2016). To gain a better understanding of training transfer, this paper reviews the literature on training transfer and proposes an explanatory model that can be subject to further empirical testing.

\section{LITERATURE REVIEW}

Since the 1950s, the problem regarding training transfer has been widely recognized as researchers found that skills and knowledge acquired from employee training often failed to transfer into work performance (Baldwin and Ford, 1988). Before 1988, most studies of training effectiveness and transfer sought to identify specific factors or separate sets of factors which were linked to training transfer. However, in a ground-breaking publication in 1988, Baldwin and Ford (1988) introduced a system model of the training transfer process. Since then, training transfer has been commonly understood as being influenced by a system of factors (Holton III et al., 2000). Given this major shift in thinking, this literature review only includes training transfer models developed since 1988. 
Baldwin and Ford (1988)'s model of the transfer process was proposed based on a comprehensive review of previous studies published from the 1950 s to the 1980 s. The model indicates that factors affecting training transfer could be divided into three sets: trainee characteristics, training design, and the work environment.

Five years later, Rouiller and Goldstein (1993) introduced a model indicating that training transfer is affected by the prevailing transfer climate at the workplace. Within this model, transfer climate is considered as an individual's perception of the extent to which the work environment facilitates or inhibits their application of learned skills and knowledge.

Based on Rouiller and Goldstein's work, Thayer and Teachout (1995) introduced a more comprehensive model of training transfer. Apart from the impact of transfer climate, this model suggests that individual characteristics play a crucial role in the success of training transfer.

Later, Holton III et al. (2000) developed and validated an instrument called the Learning Transfer System Inventory (LTSI), which introduces many individual characteristics, as well as factors related to training design and the work environment as determinants of training transfer. The LTSI recognizes the central role of motivation in facilitating training transfer, and this positioning of motivation as playing a key role has become commonly accepted (Gegenfurtner et al., 2009).

\section{TRAINING TRANSFER AS THE RESULT OF RATIONAL DECISION-MAKING PROCESS}

Previous models of training transfer provide many factors potentially affecting the application of learned skills and knowledge in practice. However, Cheng and Hampson (2008) emphasized that those models may not be sufficient to fully explain the training transfer phenomenon because of contradictory and unexpected findings arising from many empirical studies. Gegenfurtner et al. (2009) argued a flaw inherent in most training transfer models is that they oversimplify motivation. The term motivation is multidimensional, 
but most models do not reflect this multidimensionality. Thus, further research needs to be conducted to better understand training transfer from the motivational point of view. Baldwin et al. (2009) suggested that training transfer should be considered as an issue of personal choice. Hence, rather than attempting to identify factors affecting training transfer, it is arguably helpful to find answers to the underlying question: why do trainees choose to apply or not to apply acquired skills and knowledge at work?

Training transfer is defined as the extent to which trainees apply acquired skills and knowledge in practice. Although training transfer is a complex phenomenon, the application of learned skills and knowledge at work is a specific human action. Hence, training transfer can be considered as the result of individual cognitive selection of whether to perform this action or not. If we assume that the transfer action is performed as the result of trainees' rational decision-making processes, we can explain why they choose to do so by adapting the Theory of Planned Behaviour (TPB), which has been applied to predict a wide range of actions (Godin and Kok, 1996). However, little research has been conducted to explain training transfer based on the TPB's perspective (Cheng and Hampson, 2008).

\section{THE THEORY OF PLANNED BEHAVIOUR}

The TPB assumes that an individual's choice to perform or not to perform an action is rational, and this decision making is based on information they perceive from their environment (Ajzen, 1991). The theory suggests that intention is the direct antecedent of behaviour. In turn, intention is determined by three components:

- attitude toward the behaviour,

- subjective norms, and

- perceived behavioural control. 


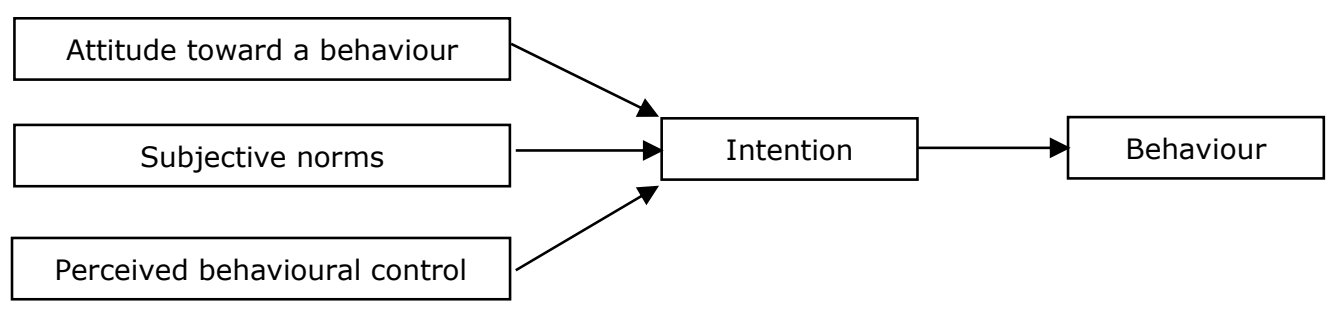

Figure 1: The Theory of Planned Behaviour

(Source: Ajzen, 1991)

According to Ajzen (2002a), attitude toward a behaviour often involves two components:

- an instrumental component representing the extent to which an individual values consequences (e.g. benefit or rewards) when performing the behaviour in question, and

- an experiential component reflecting the extent to which this individual takes pleasure in or enjoy performing the behaviour.

The first component refers to extrinsic motivation which indicates the goal-driven reasons for performing a certain behaviour (Ryan and Deci, 2000). The second component refers to intrinsic motivation that focuses on the pleasure an individual derives as a result of performing a behaviour (Ryan and Deci, 2000).

Within the TPB, subjective norms are conceptualized as injunctive norms (Ajzen, 1991). However, there are two separated types of norms: injunctive norms and descriptive norms (Cialdini et al., 1990). Injunctive norms refer to social pressures to perform a behaviour based on an individual's perception of what other people want them to do. Descriptive norms refer to social pressures to perform the behaviour based on the individual perception that other people also do so. Because of the absence of descriptive norms in the TPB, Armitage and Conner (2001) argued that subjective norms are the weakest determinants of intention. Therefore, Ajzen (2002a) recommended including both types of norms when adapting or using the TPB to explain a particular behaviour. 
According to Ajzen (2002b), perceived behavioural control involves two aspects:

- an aspect reflecting an individual's perception of the ease/difficulty of performing an action or the likelihood that the action can be performed, and

- an aspect indicating the individual perception that they have control over the action.

In other words, perceived behavioural control is determined by perceived self-efficacy and perceived controllability.

\section{A TRAINING TRANSFER MODEL BASED ON THE THEORY OF PLANNED BEHAVIOUR}

The TPB indicates that intention to perform an action is the direct antecedent of this behaviour. If training transfer is considered as a particular behaviour, its direct antecedent will be intention to transfer. Ajzen (1991) argued that intention refers to a motivation factor that affects behaviour. Hence, intention to transfer and motivation to transfer are synonymous in the context of the TPB. Motivation to transfer has widely been considered as the central factor influencing training transfer (Baldwin and Ford, 1988; Holton III et al., 2000; Bunch, 2007). Also, the TPB suggests that motivation to transfer is determined by attitude toward, subjective norms of, and perceived behavioural control over training transfer.

\section{Factors affecting attitude toward training transfer}

When considering the specific action of training transfer, attitude toward this behaviour can be defined as a trainee's overall evaluation of applying acquired skills and knowledge at work. The evaluation entails a consideration of the likely outcomes of performing this behaviour. Previous research has found that factors affecting intrinsic motivation such as perceived enjoyment or satisfaction when performing training transfer have a positive impact on motivation to transfer (Smith et al., 2008). When employees perceive that they feel pleasure in or enjoy using new skills and knowledge, they are likely to develop the willingness to perform 
transfer action. Also, factors influencing extrinsic motivation such as improving work performance, achieving rewards, or avoiding punishment as the results of performing training transfer have been widely found to predict motivation to transfer (Bates and Holton III, 2004; Devos et al., 2007).

\section{Factors affecting subjective norms of training transfer}

Previous empirical studies have proposed that injunctive norms such as perceived organizational learning culture and social support play a crucial role in determining motivation to transfer. Organizational learning culture reflecting beliefs and values about the importance or benefit of applying learned skills and knowledge has been identified as a factor affecting transfer motivation (Bates and Holton III, 2004; Egan et al., 2004). If employees perceive that their organizations encourage them to apply new skills and knowledge in practice, they are likely to do so. At work, supervisor support may influence employees' motivation to use acquired skills and knowledge (Bates and Holton III, 2004; Kirwan and Birchall, 2006). When receiving supervisor encouragement, guidance, or goalsetting regarding using learned skills and knowledge, employees would develop the perception that their supervisors want them to transfer training. Additionally, peer support is even more effective than supervisor support regarding facilitating motivation to transfer (Bates and Holton III, 2004; Devos et al., 2007). When obtaining peer encouragement or support regarding using new skills and knowledge, employees may perceive that their colleagues expect them to do so. Furthermore, feedback from supervisors and peers about how well employees are applying learned skills and knowledge may have an impact on motivation to transfer (Bates and Holton III, 2004; Kirwan and Birchall, 2006). This type of feedback can make employees recognize that most people at their workplace expect them to perform training transfer.

Additionally, descriptive norms may have an impact on motivation to transfer. If employees observe that their colleagues do not use learned skills and knowledge (team/group resistance to change), this can discourage their willingness to transfer training (Devos et al., 2007). On the contrary, if employees perceive that their peers 
apply new skills and knowledge, they may be more likely to do the same thing.

\section{Factors affecting perceived behavioural control over training transfer}

Post-training self-efficacy has long been considered as an antecedent of motivation to transfer (Noe and Wilk, 1993; Axtell et al., 1997; Chiaburu and Lindsay, 2008). If employees think that applying acquired skills and knowledge is easy to do and believe this action can be done, they may be motivated to perform training transfer. However, if employees do not believe they are able to use learned skills and knowledge, this perception may negatively affect their willingness to perform it. Additionally, even with high selfefficacy, employees may not use acquired skills and knowledge if their workplace provides insufficient enabling tasks or resources (e.g. equipment, materials, supplies) for them to do so. Hence, the opportunity to transfer training is a crucial factor influencing transfer motivation (Bates and Holton III, 2004). Also, employees may perceive themselves to have more control over training transfer when they receive adequate social support (e.g. supervisor support, peer support, feedback).

The prerequisite of training transfer is training. Without sufficient understanding and retention of the training content, employees cannot perform their expected transfer action. On the contrary, learned skills and knowledge provide employees with an opportunity to transfer training. Previous research indicated that trainees who successfully acquire the training contain are likely to develop their willingness to perform transfer action (Facteau et al., 1995). In other words, the success of training may have a positive impact on trainees' motivation to transfer. Thus, training should be designed and delivered effectively for trainees to learn and retain new skills and knowledge (Baldwin and Ford, 1988; Bates and Holton III, 2004). Also, individual characteristics such as motivation to learn (LePine et al., 2004), pre-training self-efficacy (Mathieu et al., 1992), job attitudes (Noe and Schmitt, 1986), and reaction to training (e.g. trainees' engagement with the instructional methods) (Kirkpatrick, 1998) may influence the success of training. 
In summary, a conceptual model of training transfer adapted from the TPB is shown in Figure 2.

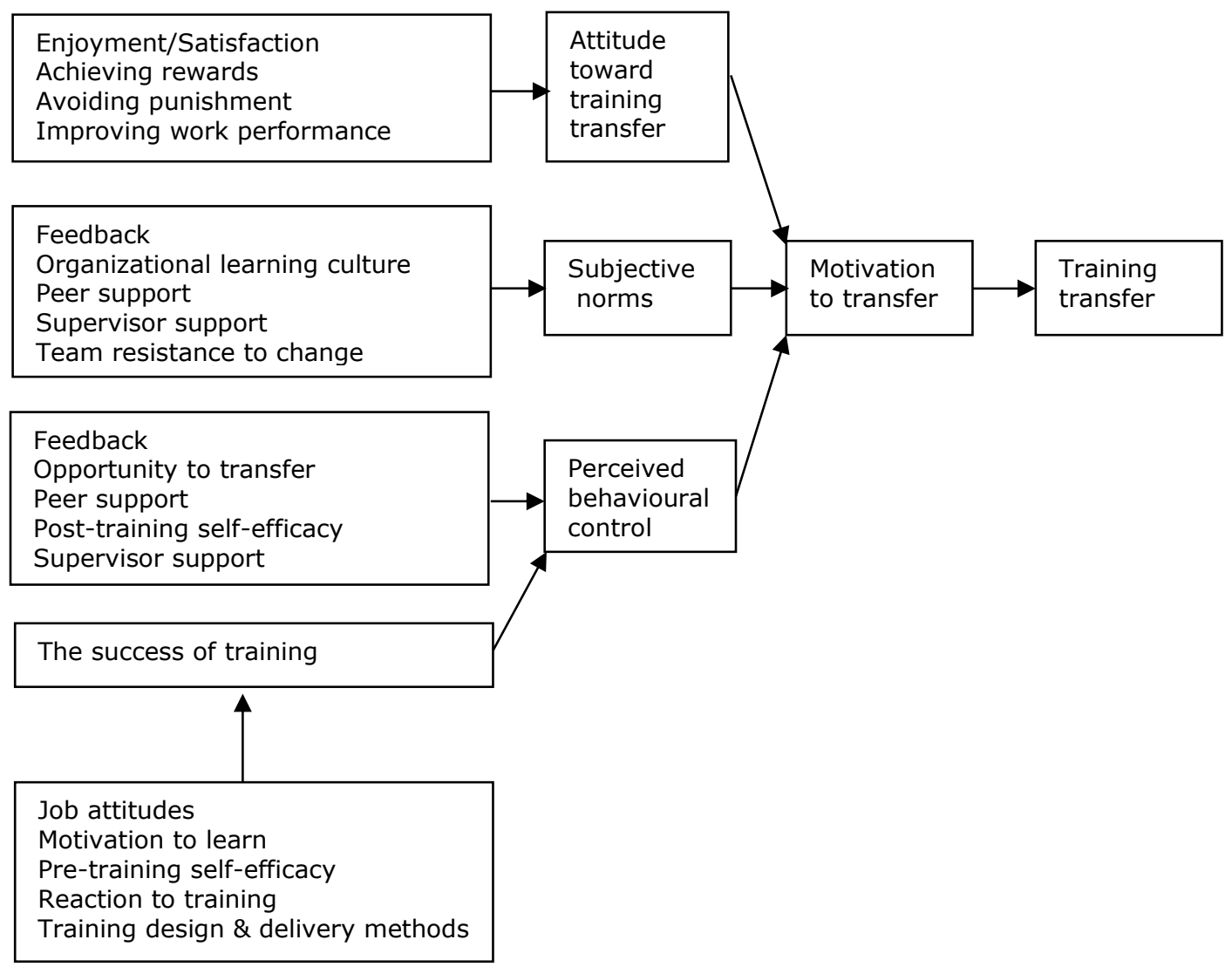

Figure 2: The conceptual model of training transfer

\section{CONCLUSION}

After seven decades, training transfer is still a challenge for industries, including the construction industry. Many models of training transfer have been introduced, but they are not supported by strong theoretical foundations. The TPB, which is a robust theory in psychology, may play a role in explaining and understanding the training transfer phenomenon. Based on this expectation, this paper proposed a conceptual model adapted from the TPB. In the following stage, an empirical study will be conducted to validate and refine 
this model to explain why training transfer happens, with a focus on the construction context. Also, because training is the prerequisite of training transfer, it is crucial to investigate how training transfer occurs in different training approaches. By doing so, we can gain a deeper understanding of training transfer, then develop appropriate strategies to facilitate employees' application of learned skills and knowledge in practice.

\section{REFERENCES}

Ajzen, I. (1991). 'The theory of planned behavior', Organizational behavior and human decision processes, Vol. 50, pp. 179-211.

Ajzen, I. (2002a). 'Constructing a TPB questionnaire: Conceptual and methodological considerations', Vol., pp. 1-14.

Ajzen, I. (2002b). 'Perceived behavioral control, Self-Efficacy, locus of control, and the theory of planned Behavior1', Journal of applied social psychology, Vol. 32, pp. 665-683.

Armitage, C. J. \& Conner, M. (2001). 'Efficacy of the theory of planned behaviour: A meta-analytic review', British journal of social psychology, Vol. 40, pp. 471-499.

Axtell, C. M., Maitlis, S. \& Yearta, S. K. (1997). 'Predicting immediate and longer-term transfer of training', Personnel Review, Vol. 26, pp. 201-213.

Baldwin, T. T. \& Ford, J. K. (1988). 'Transfer of training: A review and directions for future research', Personnel psychology, Vol. 41, pp. 63-105.

Baldwin, T. T., Ford, J. K. \& Blume, B. D. (2009). 'Transfer of training 1988-2008: An updated review and agenda for future research', International review of industrial and organizational psychology, Vol. 24, pp. 41-70.

Bates, R. \& Holton Iii, E. F. (2004). 'Linking workplace literacy skills and transfer system perceptions', Human Resource Development Quarterly, Vol. 15, pp. 153-170.

Blume, B. D., Ford, J. K., Baldwin, T. T. \& Huang, J. L. (2010). 'Transfer of training: A meta-analytic review', Journal of Management, Vol. 36, pp. 1065-1105.

Blundell, R., Dearden, L., Meghir, C. \& Sianesi, B. (1999). 'Human capital investment: the returns from education and training to 
the individual, the firm and the economy', Fiscal studies, Vol. 20, pp. 1-23.

Bunch, K. J. (2007). 'Training failure as a consequence of organizational culture', Human Resource Development Review, Vol. 6, pp. 142-163.

Cheng, E. W. \& Hampson, I. (2008). 'Transfer of training: A review and new insights', International Journal of Management Reviews, Vol. 10, pp. 327-341.

Chiaburu, D. S. \& Lindsay, D. R. (2008). 'Can do or will do? The importance of self-efficacy and instrumentality for training transfer', Human Resource Development International, Vol. 11, pp. 199-206.

Choudhry, R. M. \& Fang, D. (2008). 'Why operatives engage in unsafe work behavior: Investigating factors on construction sites', Safety science, Vol. 46, pp. 566-584.

Cialdini, R. B., Reno, R. R. \& Kallgren, C. A. (1990). 'A focus theory of normative conduct: Recycling the concept of norms to reduce littering in public places', Journal of personality and social psychology, Vol. 58, pp. 1015.

Devos, C., Dumay, X., Bonami, M., Bates, R. \& Holton, E. (2007). 'The Learning Transfer System Inventory (LTSI) translated into French: internal structure and predictive validity', International Journal of Training and Development, Vol. 11, pp. 181-199.

Egan, T. M., Yang, B. \& Bartlett, K. R. (2004). 'The effects of organizational learning culture and job satisfaction on motivation to transfer learning and turnover intention', Human resource development quarterly, Vol. 15, pp. 279-301.

Egbu, C. O. (2004). 'Managing knowledge and intellectual capital for improved organizational innovations in the construction industry: an examination of critical success factors', Engineering, Construction and Architectural Management, Vol. 11 , pp. 301-315.

Facteau, J. D., Dobbins, G. H., Russell, J. E., Ladd, R. T. \& Kudisch, J. D. (1995). 'The influence of general perceptions of the training environment on pretraining motivation and perceived training transfer', Journal of management, Vol. 21, pp. 1-25. 
Gann, D. \& Senker, P. (1998). 'Construction skills training for the next millennium', Construction Management \& Economics, Vol. 16 , pp. 569-580.

Gegenfurtner, A., Veermans, K., Festner, D. \& Gruber, H. (2009). 'Motivation to transfer training: An integrative literature review', Human Resource Development Review, Vol., pp.

Godin, G. \& Kok, G. (1996). 'The theory of planned behavior: a review of its applications to health-related behaviors', American journal of health promotion, Vol. 11, pp. 87-98.

Grossman, R. \& Salas, E. (2011). 'The transfer of training: what really matters', International Journal of Training and Development, Vol. 15, pp. 103-120.

Holton Iii, E. F., Bates, R. A. \& Ruona, W. E. (2000). 'Development of a generalized learning transfer system inventory', Human resource development quarterly, Vol. 11, pp. 333.

Kirkpatrick, D. L. (1998). 'Evaluating training programs: the four levels', Vol., pp.

Kirwan, C. \& Birchall, D. (2006). 'Transfer of learning from management development programmes: testing the Holton model', International Journal of Training and Development, Vol. 10, pp. 252-268.

Lepine, J. A., Lepine, M. A. \& Jackson, C. L. (2004). 'Challenge and hindrance stress: relationships with exhaustion, motivation to learn, and learning performance', Journal of Applied Psychology, Vol. 89, pp. 883.

Mathieu, J. E., Tannenbaum, S. I. \& Salas, E. (1992). 'Influences of individual and situational characteristics on measures of training effectiveness', Academy of management journal, Vol. 35, pp. 828-847.

Namian, M., Albert, A., Zuluaga, C. M. \& Jaselskis, E. J. (2016). 'Improving hazard-recognition performance and safety training outcomes: Integrating strategies for training transfer', Journal of Construction Engineering and Management, Vol. 142, pp. 04016048.

Noe, R. A. \& Schmitt, N. (1986). 'The influence of trainee attitudes on training effectiveness: Test of a model', Personnel psychology, Vol. 39, pp. 497-523. 
Noe, R. A. \& Wilk, S. L. (1993). 'Investigation of the factors that influence employees' participation in development activities', Journal of applied psychology, Vol. 78, pp. 291.

Rouiller, J. Z. \& Goldstein, I. L. (1993). 'The relationship between organizational transfer climate and positive transfer of training', Human resource development quarterly, Vol. 4, pp. 377-390.

Ryan, R. M. \& Deci, E. L. (2000). 'Intrinsic and extrinsic motivations: Classic definitions and new directions', Contemporary educational psychology, Vol. 25, pp. 54-67.

Smith, R., Jayasuriya, R., Caputi, P. \& Hammer, D. (2008). 'Exploring the role of goal theory in understanding training motivation', International Journal of Training and Development, Vol. 12, pp. 54-72.

Thayer, P. W. \& Teachout, M. S. (1995). A Climate for Transfer Model. DTIC Document.

Wilkins, J. R. (2011). 'Construction workers' perceptions of health and safety training programmes', Construction Management and Economics, Vol. 29, pp. 1017-1026. 